\title{
Scientific Professionalism
}

$\mathrm{I}^{\mathrm{N}}$ contrast to the trade union movement, which has received much attention both in its historical aspects and in relation to the social and economic problems it presents, professional associations have been almost entirely neglected. There has been no study of the historical development of professional association or of the social, economic and ethical problems involved. In view of the growing importance of the expert in public life, the position and influence of professional associations possess a wide interest.

We may perhaps begin with the medical profession. Its present organisation is basert upon the Medical Act of 1858, which created the General Council of Medical Education and Registration of the United Kingdom, usually known as the General Medical Council. This Council, which is subject to the Privy Council, has two main duties, to ensure that the unfit do not get on to the register and to expunge the unworthy from it. While the General Medical Council has no option but to register those who produce a licence from a duly accredited authority and tender the prescribed fee, it is empowered to erase a name from the register in certain circumstances ; although neither teaching nor examining, it can enforce such minimum standards of education and examination as it pleases. The topics which the General Medical Council is competent to discuss are, however, limited, and exclude, for example, all questions relating to remuneration. These questions, particularly the pay and status of medical officers in the Services and under local authorities, and of practitioners under the National Health Insurance scheme, are main fields of activity of the British Medical Association, though it would be difficult to overestimate the contribution of the latter also to medical science and practice.

The British Medical Association was founded at Worcester in 1832 , although it did not assume its present title until 1856. Its membership embraces 35,000 of the 55,000 names on the medical register and probably includes three-quarters of the medical men in practice in Great Britain. Its constitution in its present form dates from 1902 and the effective control of the Association lies with the Representative Body, consisting chiefly of delegates elected by the divisions. The Representative Body is the parliament of the Association and debates at its meetings are keen. Persistent skilful leadership has played a large part in raising the status and remuneration of doctors and although there is little evidence regarding the average income of the general practitioner, it is significant that the Association is able to obtain a minimum commencing salary of $£ 600$ a year for a whole-time medical officer of the lowest grade. At the arbitration inquiry in 1926 it was stated that $£ 1,200$ might be the average income from a successful practice "not at the top". Evidence was given before the Royal Commission on the Civil Service in 1930 that a fully employed panel doctor in a populous area, using half his time for panel and half for private practice, could make $£ 1,400$ net per annum. The salaries offered to medical men are considerably higher than those for dentists or for veterinary surgeons.

The position of the veterinary surgeons presents analogies with the position of the medical profession but is weaker mainly through the neglect of veterinary science in Great Britain. The Veterinary Surgeons Act of 1881 laid upon the Royal College of Veterinary Surgeons the duty of keeping a register but, unlike the General Medical Council, also of examining the students of recognised veterinary colleges. It possesses disciplinary powers and its members have certain privileges similar to those granted to doctors. The numerical weakness of the profession-the register contains 3,473 names for the British Isles-and prevailing indifference to veterinary science largely account for the comparative impotence of the National Veterinary Medical Association.

The engineering profession offers strong contrasts to the conditions of the medical profession, particularly in the absence of any legal register and in the number of specialist organisations which have developed as the range of engineering grows. The parent society is the Institution of Civil Engineers, founded in 1818, the activities of which for the first fifty years were confined to study. For long enough membership, however, did not imply scientific training and only in 1897 did the Institution establish its own examinations. There are grades of membership, corresponding to different degrees of attainment and experience. Associates must be more than twenty-five years of age and have passed either the examinations of the Institution or an approved examination and have undergone a specified period of practical training. Members must be more than thirtythree years of age and have been associates with five years' experience in a position of responsibility, or have had "suitable education and training as a civil engineer" and fifteen years employment in a position of responsibility and have acquired "a considerable degree of eminence in the profession". Rules governing the professional conduct of members were not formed until 1910 and their general purport is to ensure that the engineer's utmost skill shall be placed at the disposal of those who employ him, and that the method of remuneration shall not involve any conflict between his personal interests and those of the clients whom he advises.

Round the Institution of Civil Engineers have sprung up the Institution of Mechanical Engineers, the Institution of Naval Architects, and the Institution of Electrical Engineers, as well as other junior institutions such as the Institution of Mining Engineers, the Institution of Structural Engineers, the Institution of Automobile Engineers, 
the Institution of Gas Engineers and the Institution of Chemical Engineers. These are not rival associations though they are modelled on the parent society and the membership overlaps considerably. The civil and mechanical engineers have memberships of about 10,000, the 'electricals' about 11,500 , the naval architects about 3,000 and the mining engineers 3,800 . The number of qualified engineers in Great Britain is estimated at 26,659 .

The professional organisation of chemists in Great Britain has been handicapped by the assumption of the title of "chemist" under the Pharmacy Act of 1868 by members of another vocation possessing one or more alternative titles. The growth of the profession is frequently referred to the formation of the Chemical Society in 1841, which, however, has remained a study society and never demanded scientific or practical qualifications of its members. The first steps at professional organisation were taken in consequence of the passing of the Sale of Food and Drugs Act in 1875, and led directly to the founding of the Institute of Chemistry in 1877. Although its interests were originally mainly limited to those of analytical and consulting chemists, since 1918 it has included a large number of those practising in industry. Its present membership of nearly 6,000 probably represents from one half to three quarters of the fully trained chemists in Great Britain.

The Institute of Chemistry has done much to raise the status of the public analyst, but it has been able to do relatively little to raise the status or remuneration of the chemist in general, and the prestige and value of its membership have not become such that all qualified to obtain it do in fact apply. More effective professional defensive work for chemists generally is being done by the British Association of Chemists, in spite of a much smaller membership-a little over 1,000 - largely on account of the greater freedom permitted by its constitution and by its registration under the trade union acts. The Institute of Chemistry is an examining body but the fellowship and associateship can be obtained with partial or complete exemption from examination by those holding recognised degrees or diplomas with first or second class honours in chemistry. The British Association of Chemists also admits those with a sufficient general education and scientific training who have had at least seven years' practice in pure or applied chemistry. The estimated number of chemists is about 10,000 of whom not more than 350 are in private practice. Inquiries conducted by the Institute of Chemistry in 1930 indicated that 15 per cent of fellows at home were receiving between $£ 1,000$ and $£ 1,500$ and nearly 50 per cent between $£ 500$ and $£ 1,000$; of associates at home 25 per cent were receiving $£ 500$ to $£ 1,000$ and 62 per cent from $£ 250$ to $£ 500$. Members abroad were getting considerably higher salaries.

Reference has been made to the pharmacists, whose early history is closely related to that of the medical professions through the apothecaries and "chemists" and "druggists". The Pharmacy Act of 1868 prohibits any person from selling or keeping open shop for retailing, dispensing or compounding specified poisons or from using the title "chemist and druggist", or "chemist", or "druggist", or "pharmacist", or "dispensing chemist", or "druggist", unless registered by the Pharmaceutical Society. Up to 1919 the latter society not only fulfilled its statutory obligations of examining and registering but it also looked after both the professional and trading interests of pharmacists. In consequence of the judgment in a test case in 1920 the Retail Pharmacists' Union was established, to which were transferred all employers' functions and those of negotiating with the Government regarding the National Health Insurance Act.

Up to the formation of the Institute of Physics in 1920 the physicist had scarcely been recognised as one of the professions, being mainly confined to the universities. The increasing demand for physicists in industry led to the formation of the Institute, which differs considerably in constitution from the Institute of Chemistry. Members of any of five participating societies, which are study associations, can become ordinary members, but the corporate members in whom authority is vested consist of fellows and associates who must have passed either the examination of the Institute or an equivalent examination. Fellows in addition must have had five years' experience. There are 600-700 corporate members and the Institute of Physics has a much more effective command of the profession than has the Institute of Chemistry.

The emergence of the true patent agent possessing a skill partly legal and partly scientific is of comparatively recent date, and the number of qualified patent agents in Great Britain and Ireland is only 343. Since, however, salaried employees in a patent agency are not required to register, there are many qualified persons who have fulfilled all the requirements but have not proceeded to registration. A register of patent agents was established by the Act of 1888 , but effective protection was only conferred by the subsequent Patent and Designs Act of 1919, which lays it down categorically that "no person shall practice ... as a patent agent, unless ... he is registered". The register is kept by the Institute of Patent Agents and admission is confined to those who have passed a preliminary, an intermediate and a final examination conducted by the Institute. Candidates for the final examination must have served for five years in the office of a registered patent agent, although articles are not obligatory and some exception is granted to those who have graduated at a university or spent a specified time at an approved technical college, or an approved profession or industry or on the examining staff of the Patent Office. In spite of its important educational duties, the Chartered Institute of Patent Agents is a voluntary associa- 
tion and only about two-thirds of the registered patent agents are members.

The recently published work by Prof. A. M. Carr-Saunders and Mr. P. A. Wilson* on the growth and position of the professions, on which the above remarks have been based, is a welcome and valuable attempt to fill a serious gap. The first part gives a survey of the present position of the recognised professions and of other occupations with more or less definite claims to be recognised as professions, and forms an invaluable reference work with regard to qualifications, numbers of practitioners, salaries or positions obtainable in a wide range of professions.

Special interest is attached to the sections dealing

" "The Professions". By A. M. Carr-Saunders and P. A. Wilson. Pp. viii +536 . (Oxford: Clarendon Press; London: Oxford University Press, 1933.) 25s, net. with architects and with teachers, one on account of the recent efforts to obtain a registration which issued in the Architects (Registration) Act of 1931, the other on account of the growth of unity in a profession formerly separated by deep-seated jealousies and also on account of the influence of widespread State employment leading to what is in effect a State register of teachers. So, too, the analysis of the conditions which led to public accordance of professional status to the civil service and to local government service, and of those again which prevail in the mercantile marine or among mine managers, are invaluable to all scientific workers who seek to understand the place and functions of professionalism in modern society and to assess the contribution which registration can offer alike to the advance of the professions or of the State they serve.

\section{Taxonomy and Evolution}

By Dr. W. H. Longley, Marine Biological Laboratory, Tortugas, Florida.

$\mathrm{T}$ EN years ago Dr. J. C. Willis developed in his work "Age and Area" his discovery of the existence of an unexpected order in Nature revealed by statistical analysis of selected data of taxonomy. Prof. Bateson expressed keen appreciation of this discovery in a review of the work in NATURE ${ }^{1}$. The sign of order represented was, in Bateson's judgment, highly significant and is the central fact to which the present contribution is related.

In the great natural groups of organisms-the larger families and orders-the statistical distribution of genera by size is approximately the same in all cases; or, to put it in other words, the curve of genera plotted against the number of their species is always of the same general form. This suggests at once that the process of evolution occurs according to law. Indeed, only if the naturalist's conception of genera and species is without justification in the order of Nature itself, or if his classification of material given by Nature is grossly inadequate, may the direct inference be avoided. But, letting the necessary inquiry this suggests rest for the moment, is there independent reason for supposing the process of differentiation of genera and species of organisms may occur according to law?

Manifestly such law as is suggested by Dr. Willis's discovery is one of a statistical sort, a description of the outcome of the evolutionary process as a whole and without regard to detaila law, indeed, of the general order of the gas laws of physics, where the individual is quite lost to sight. If it be urged that such laws do not deal with underlying truths, it may be admitted at once that they are not exhaustive accounts of the events in systems of which they treat: but they are still laws, and laws, too, of a high order of importance.

The laws of gases (with similar statistical laws) have, in fact, served as the foundation, from one point of view, of our modern industrial civilisation, with all that it entails. If to know how things go, on the whole, with molecules in the gaseous systems they compose, has shown itself so significant a matter, we may believe that the like knowledge of what is involved in the making of genera and species will justify itself. It requires no lively imagination to foresee some of its effects upon our thought, where its important application will chiefly lie.

To consider the gas laws further: these are generalisations empirically established and the basis upon which the kinetic theory of gases rests. It is from them that we derive our idea that the normal gas is a system of ultra-microscopic particles, active and acting at random, incapable of reproduction and variation, capable of exerting an influence upon one another measurable at last as pressure against the weight of a column of supported fluid.

Now clearly there is no theoretical reason why there might not be systems of units differing from molecules in few or many respects, but still active and acting on one another at random, and on that account having among their laws some of the form of the gas laws. Such systems might be composed of macroscopic, as well as of ultra-microscopic units, units capable of exercising some other influence upon one another than that measurable after the precise fashion of gas pressures, units capable of varying or of increasing their number by some sort of reproductive process, or of at once reproducing and varying.

To express such ideas is only to suggest that the kinetic theory of gases is capable of generalisation, and of being applied, mutatis mutandis, to a variety of systems, real or imaginary : call them 'kinetic systems', systems the units of which, whatever they may be, are active and act upon others of their kind at random. 